UDC 316.34

LBC 60.561 .2

\title{
STRATEGIC PRIORITIES \\ OF IMPROVING THE PROFESSIONAL COMPETENCY OF WORKERS OF AGRICULTURE
}

\author{
Elena V. Bocharova \\ Institute of Agrarian Problems of the Russian Academy of Sciences, Saratov, Russian Federation
}

\begin{abstract}
In the context of increasing competitiveness, the relevance of justifying strategic priorities for improving the professional competencies of employees of the Russian agro-industrial complex is significantly increasing. There is a need to develop proposals for the formation, implementation and control of strategic management based on the proposed priorities. Research methodology based on data from the 26 waves of "Russian monitoring of economic situation and population health, (RLMS-HSE)", and also on materials of Federal state statistics service of the Russian Federation. This document systematizes Russian and foreign methodological approaches to the study of professional competencies of agricultural workers. The article substantiates the need to apply a competence-based approach in the field of strategic personnel management in the agricultural sector of the economy. The modern approach to assessing professional competencies is based on the need to identify various factors that affect the content of employees' work and improve the efficiency of the work performed. This approach will allow us to develop recommendations for the formation, implementation and development of a mechanism for improving the professional competencies of workers in agriculture in the Russian Federation. Agriculture is still an economic sector that employs many low-skilled workers. Proposals are needed for the formation, implementation and control of strategic personnel management in the agricultural sector of the economy. The main priorities for the development of professional competencies of industry employees were determined based on the analysis of state programs for personnel support. The main directions are: modernization of the entire system of training and retraining of agricultural workers, participation of individuals in the process of continuing education using the existing potential of state and public institutions, creating comfortable working conditions, as well as improving the system of material and non-material incentives for personnel. Federal and regional authorities, as well as enterprise management, can use the theoretical and methodological conclusions of this article when developing a strategy for staffing agriculture. The practical significance of this work lies in this.
\end{abstract}

Key words: competency, worker, agriculture, competitiveness, knowledge, skills, ability.

УДК 316.34

ББК 60.561 .2

\section{СТРАТЕГИЧЕСКИЕ ПРИОРИТЕТЫ СОВЕРШЕНСТВОВАНИЯ ПРОФЕССИОНАЛЬНЫХ КОМПЕТЕНЦИЙ РАБОТНИКОВ СЕЛЬСКОГО ХОЗЯЙСТВА}

\section{Елена Викторовна Бочарова}

Институт аграрных проблем РАН, г. Саратов, Российская Федерация

Аннотация. В условиях повышения конкурентоспособности существенно возрастает актуальность
обоснования стратегических приоритетов совершенствования профессиональных компетенций работников
российского агропромышленного комплекса и разработки предложений по формированию, реализации и
контролю в области стратегического управления на основе предложенных приоритетов. Методика исследо-
вания построена на данных 26-й волны «Российского мониторинга экономического положения и здоровья 
населения НИУ-ВШЭ (RLMS-HSE)», а также материалах Федеральной службы государственной статистики РФ. Осуществлена систематизация отечественных и западных методологических подходов к изучению профессиональных компетенций работников сельского хозяйства. В статье обосновывается необходимость применения компетентностного подхода в области стратегического управления кадровым обеспечением аграрного сектора экономики. Современный взгляд по вопросу оценки профессиональных компетенций исходит из необходимости выявления совокупности различных факторов, которые влияют на содержание труда сотрудников с целью повышения эффективности выполняемой работы. Такой подход способствует разработке рекомендаций по формированию, реализации и развитию механизма совершенствования профессиональных компетенций работников в сельском хозяйстве РФ. Последнее по-прежнему является отраслью экономики, в которой много малоквалифицированных кадров. Необходимы предложения по формированию, реализации и контролю в области стратегического управления кадровым обеспечением аграрного сектора экономики. На основе проведенного анализа государственных программ по кадровому обеспечению сельскохозяйственной сферы определены основные приоритеты развития профессиональных компетенций работников отрасли. Основными направлениями являются: модернизация всей системы подготовки и переподготовки работников аграрной сферы, участие индивидов в процессе непрерывного образования с использованием имеющегося потенциала государственных и общественных институтов, создание комфортных условий труда, а также улучшение системы материального и нематериального поощрения персонала. Практическая значимость полученных результатов определяется возможностью использования федеральными, региональными органами власти, а также руководством предприятий теоретических и методологических предложений при разработке стратегии кадрового обеспечения сельского хозяйства.

Ключевые слова: компетенция, работник, сельское хозяйство, конкурентоспособность, знания, умения, навыки.

\section{Введение}

Актуальность исследования. В последние годы в социально-трудовой сфере российского сельского хозяйства наблюдаются следующие негативные тенденции: снижение занятости, угроза роста безработицы, увеличение расслоения населения (на уровне регионов, отдельных хозяйств), ухудшение качества рабочей силы, снижение значимости труда в аграрной сфере, а также уменьшение инвестиционной привлекательности сельской местности.

С целью эффективного и рационального использования ресурсов сельского хозяйства отрасли необходимы высококомпетентные кадры, занятые в сельскохозяйственных организациях, фермерских хозяйствах и хозяйствах населения.

Степень разработанности проблемы. Выделим основные методологические подходы к пониманию профессиональных компетенций работников аграрного сектора:

1. Поведенческий подход, изучающий компетенции через поступки работника [White 1959]. Родоначальник американского подхода Дэвид Макклелланд [McClelland 1973] изучал действия сотрудника по повышению эффективности в процессе труда.Ученый пришел к заключению, что работник обязательно ста- рается следовать определенным поведенческим индикаторам. Компетенция в рамках данного подхода - это характеристика индивида, помогающая добиться высоких показателей в трудовой деятельности.

2. В рамках функционального подхода [Winterton, Delamare Le Deist, Stringfellow 2006] профессиональная компетенция понимается как способность действовать в организации исключительно в пределах принятых стандартов.

3. Суть экспертного подхода [Chi 2006, 22] заключается в рассмотрении компетенций работников через познание. В качестве предмета анализа выступают профессиональные качества экспертов как сотрудников, достигших наивысших показателей успеха в своей деятельности.

4. Отечественный подход к проблеме предполагает анализ профессиональных компетенций в парадигме знаний, умений, навыков [Ефремова 2010; Хуторской 2003].

Учитывая негативные демографические тренды, в будущем необходимо рассчитывать на меньшее число занятых, но более компетентных в аграрной сфере сотрудников. Исходя из этого, повышается интерес к интегративному подходу, объединяющему разработки «знаниевой» парадигмы, а также постулаты западных школ. По нашему мнению, каж- 
дый заинтересованный работник сельского хозяйства должен иметь возможность совершенствовать профессиональные компетенции, а именно полученные знания, дополнительные умения, профессиональные навыки, способы осуществления трудовой деятельности, необходимые для эффективного выполнения поставленных трудовых задач [Бочарова 2017, 136].

Цель данной работы состоит в обосновании стратегических приоритетов развития профессиональных компетенций работников сельскохозяйственной отрасли для выработки кадровой стратегии агропромышленного сектора.

Методика исследования построена на данных Федеральной службы государственной статистики РФ, а также материалах 26-й волны «Российского мониторинга экономического положения и здоровья населения НИУ-ВШЭ (RLMS-HSE)», (2017 год, $\mathrm{N}=$ 214 , ограничена респондентами, работающими в агропродовольственном комплексе) [Российский мониторинг... web].

Занятость в аграрном секторе экономики в 2017 г. составляла 4212 тыс. чел., то есть $5,8 \%$ от общей численности трудящихся. В настоящее время в сельскохозяйственных организациях РФ работают 12,4 \% специалистов, имеющих высшее образование, однако аграрное образование лишь у $6,7 \%$ из их числа. Среднее профессиональное образование получили $21,2 \%$ работников отрасли, из них сельскохозяйственное $-9,8 \%$. Начальное профессиональное образование имеет каждый пятый занятый сельскохозяйственным трудом. Наибольшая часть (43,6 \%) работников агропредприятий по-прежнему не имеет специального профессионального образования [Предварительные итоги... 2017, 70]. Сельскохозяйственной деятельностью в основном занимаются мужчины (67,1 \%), женщины составляют около трети занятых (32,9\%). Доля молодых специалистов (до 30 лет) в возрастной структуре занятых составляет $17,8 \%$. Каждый восьмой сотрудник в сельском хозяйстве старше 60 лет. Средний возраст работников в сельскохозяйственной отрасли составляет 42,9 года [Рабочая сила, занятость... 2018, 48, 50, 54].

На основе данных «Российского мониторинга экономического положения и здоро- вья населения НИУ-ВШЭ (RLMS-HSE)» (РМЭЗ НИУ ВШЭ), проведенного в 2017 г. [Российский мониторинг... web], обратимся к характеристике работников по уровню образования и квалификации.

В сельском хозяйстве каждый пятый работник имеет среднее профессиональное образование (ПТУ). В возрастной категории 45-54 года около трети $(31,5 \%)$ сотрудников указали профессионально-техническое училище как самый высокий уровень полученного ими образования. Среднее общее образование получил каждый десятый опрошенный респондент (16-34 года - 10,4 \%; 35-44 года 8,5 \%; 45-54 года - 9,3 \%; 55-64 года - 8,9 \%; 65 лет и старше - 12,5\%). Четверть молодых работников до 34 лет имеют неполное среднее образование. Одна треть работников сельского хозяйства пенсионного возраста указали профессиональные курсы (шоферов, трактористов и т. д.) как самый высокий уровень образования, по которому был получен диплом, аттестат, свидетельство. Невысокий уровень образования в старших возрастных категориях обусловлен историческими особенностями страны: в советское время были востребованы рабочие профессии в сельском хозяйстве. Среднее профессиональное образование (техникум) имеют $15 \%$ работников аграрной отрасли. Таким образом, сельское хозяйство по-прежнему является отраслью экономики, которая функционирует благодаря малоквалифицированным кадрам. Эта социально-профессиональная группа может быть привлечена руководством организаций для выполнения разного рода работ. Работники, имеющие высшее образование (16-34 года $17 \%$; 35-44 года - 13,6 \%; 45-54 года - 5,6 \%; 55-64 года - 8,9 \%; 65 лет и старше - 12,5\%), могут рассчитывать на достойную должность, рост материального благополучия, уважение руководства и сотрудников. Аграрное образование является специфической формой профобразования, которое уделяет особое внимание практике, максимально приближенной к реальным условиям функционирования отрасли. В связи с этим содержание учебных программ должно соответствовать пожеланиям и потребностям работников, учитывая их интересы, уровень квалификации, мотивации; ориентироваться на развитие профессиональ- 
E.B. Бочарова. Стратегические приоритеты совершенствования профессиональных компетенций

ных компетенций специалистов. Представители аграрной сферы могут задавать стандарты обучения, осуществляя составление и аккредитацию образовательных программ, а также участвовать в их финансировании.

Доля квалифицированных работников сельского хозяйства во всех возрастных категориях, кроме самой старшей, составляет около 60 \%. Каждый пятый неквалифицированный сотрудник занимается на своем рабочем месте такими работами, как посадка, сбор сельскохозяйственных культур, а также уход за животными. В аграрной сфере наблюдается дефицит специалистов среднего и высшего уровня квалификации трудоспособного возраста. Это связано с особенностями локальных рынков труда, поощряющих слабоэффективные рабочие места (табл. 1).

Гарантом продуктивной работы в сельском хозяйстве является хорошее самочувствие сотрудников, что опосредованно влияет на желание совершенствовать профессиональные компетенции. В целом самооценка состояния здоровья находится на достойном уров- не. Большая часть молодых специалистов $(81,2$ \%) оценили свое самочувствие как хорошее. Каких-либо хронических заболеваний они не имеют. Вполне закономерно, что с увеличением возраста пропорционально сокращается количество персонала, положительно оценивающего свое здоровье. Более половины работников $(57,6 \%)$ в возрасте $35-$ 44 года охарактеризовали свое здоровье как «хорошее» с возможностью плодотворно и эффективно трудиться. Работники старше 45 лет (более $60 \%$ ) оценили самочувствие как «удовлетворительное». На плохое самочувствие жалуются сельхозтоваропроизводители старших возрастных групп (45-54 года 7,4 \%; 55-64 года - 11,1\%; 65 лет и старше $12,5 \%$ ). Здоровье очень хорошим считают лишь 1,7 \% трудящихся в возрасте $35-44$ года (табл. 2).

Таким образом, работники в основном оценивают свое здоровье как хорошее в молодом возрасте и среднее - в более зрелом. Положительная оценка здоровья отражает субъективное восприятие конкретного человека.

Таблица 1

\section{Структура занятого в сельском хозяйстве РФ населения по возрасту и группам занятий}

\begin{tabular}{|l|c|c|c|c|c|}
\hline \multicolumn{1}{|c|}{ Специалисты } & \multicolumn{5}{|c|}{ Возраст } \\
\cline { 2 - 6 } & $16-34$ лет & $35-44$ лет & $45-54$ лет & $55-64$ лет & $\begin{array}{l}65 \text { лет и } \\
\text { более }\end{array}$ \\
\hline $\begin{array}{l}\text { Руково дители высшего и среднего } \\
\text { звена }\end{array}$ & 4,2 & - & 5,6 & 6,7 & - \\
\hline $\begin{array}{l}\text { Специалисты высшего уровня } \\
\text { квалификации }\end{array}$ & 4,2 & 5,1 & 1,9 & 2,2 & 25 \\
\hline $\begin{array}{l}\text { Специалисты среднего уровня } \\
\text { квалификации }\end{array}$ & 10,4 & 13,6 & 11,1 & 8,9 & 12,5 \\
\hline Офисные служащие & 8,3 & 1,7 & 3,7 & 2,2 & 37,5 \\
\hline Квалифицированные работники & 54,1 & 57,6 & 59,2 & 58 & 12,5 \\
\hline Неквалифицированные работники & 18,8 & 22 & 18,5 & 22 & 12,5 \\
\hline \multicolumn{1}{|c|}{ Итого } & 100 & 100 & 100 & 100 & 100 \\
\hline
\end{tabular}

Примечание. Источник: [Российский мониторинг... web].

\section{Самооценка состояния здоровья}

\begin{tabular}{|l|c|c|c|c|c|}
\hline \multirow{2}{*}{ Состояние здоровья } & \multicolumn{5}{|c|}{ Возраст } \\
\cline { 2 - 6 } & $16-34$ лет & $35-44$ лет & $45-54$ лет & $55-64$ лет & 65 лет и более \\
\hline Очень хорошее & - & 1,7 & - & - & - \\
\hline Хорошее & 81,2 & 57,6 & 31,5 & 22,2 & 12,5 \\
\hline Среднее & 18,8 & 40,7 & 61,1 & 66,7 & 62,5 \\
\hline Плохое & - & - & 7,4 & 11,1 & 12,5 \\
\hline Очень плохое & - & - & - & - & 12,5 \\
\hline \multicolumn{1}{r|}{ Итого } & 100 & 100 & 100 & 100 & 100 \\
\hline
\end{tabular}

Примечание. Источник: [Российский мониторинг... web]. 


\section{НАУЧНЫЕ СООБЩЕНИЯ}

В определенной степени это связано с улучшением качества медицинских услуг, внедрением и распространением высокотехнологичной помощи, улучшением обеспеченности узкопрофильными специалистами. Показатели здоровья должны соотноситься с выполняемой работой в организации и содействовать лучшей интеграции в социальную среду коллектива.

Достаточно высокие показатели физической активности представителей всех возрастных категорий способствуют тому, что почти половина опрошенных (49,5 \%) работают 8 часов в день. Для некоторых тружеников характерно отступление от нормального (8-часового) рабочего дня. Режим работы 10-часовой продолжительности в течение дня характерен для $12,6 \%$ сельскохозяйственных тружеников, около $20 \%$ занятых трудятся более 12 часов в день. Активные работники не всегда используют свои шансы удачно и плодотворно интегрировать навыки, умения и знания в подходящие рыночные ниши. Одна из главных причин такой ситуации - низкий уровень профессиональных компетенций сотрудников, сложившийся режим трудовой нагрузки. В такой ситуации трудно ожидать проявление инициатив работников по участию в организованных формах повышения квалификации.

В связи с этим назрела необходимость разработки предложений по формированию, реализации и контролю в области стратегического управления кадровым обеспечением аграрного сектора экономики. В процесс реализации стратегических приоритетов должны быть вовлечены федеральные, региональные органы власти, а также руководство предприятий, полномочные представители Федеральных округов РФ, образовательные структуры, успешные работники агросферы, профессиональные союзы и ассоциации, заинтересованные в росте производительности АПК.

Основными документами по развитию кадрового обеспечения в сельскохозяйственной отрасли являются: Указ Президента РФ от 7 мая 2018 г. № 204 «О национальных целях и стратегических задачах развития Российской Федерации на период до 2024 года» [Указ Президента РФ от 7 мая 2018 года... web], Паспорт национального проекта «Производительность труда и поддержка занятос- ти» [Национальные проекты... web], Указ Президента РФ от 21 июля 2016 г. № 350 «О мерах по реализации государственной научно-технической политики в интересах развития сельского хозяйства», Федеральная научно-техническая программа развития сельского хозяйства на 2017-2025 гг. [Постановление Правительства РФ от 25 августа 2017 года... web], Государственная программа развития сельского хозяйства и регулирования рынков сельскохозяйственной продукции, сырья и продовольствия на 2013-2020 гг. [О переводе... web], Государственная программа «Содействие занятости населения» [О внесении изменений... web]. Учитывая национальную важность поддержания продовольственной безопасности, развитие сельского хозяйства должно отражать интересы не только предпринимателей, но и государства.

Основными проблемами развития сельского хозяйства в нашей стране являются: пространственная удаленность сельскохозяйственных предприятий, что требует особого сочетания личных и профессиональных качеств специалистов, готовности самостоятельного принятия управленческих решений; удаленность объектов социальной инфраструктуры, бытовая необустроенность жилого фонда, что приводит к определенному затруднению при решении профессиональных задач; ограниченность аграрного рынка труда; низкая степень мобильности населения из-за высокой степени привязанности к выбранному месту работы; финансовая нестабильность многих сельскохозяйственных производств затрудняет планирование этапов самосовершенствования, роста профессиональных компетенций.

\section{Вывод}

Таким образом, на основе проведенного анализа качественных и количественных характеристик работников аграрной сферы определены стратегические приоритеты развития их профессиональных компетенций с учетом проводимой политики кадрового обеспечения отрасли носителями качественных и требуемых компетенций. Основными приоритетами являются:

- взаимодействие органов власти, различных отраслей народного хозяйства (сель- 
E.В. Бочарова. Стратегические приоритеты совершенствования профессиональных компетенций

ское хозяйство, промышленность, транспорт и связь, жилищно-коммунальное хозяйство, здравоохранение, образование и т. д.) и общественности в целях дальнейшего планирования трудовой карьеры специалистов и развития их профессиональных компетенций;

- модернизация существующих программ подготовки и переподготовки специалистов аграрного профиля с целью их ориентации на компетентностный подход;

- поэтапная интеграция образования, науки и практики;

- прогнозированиепотребности сельскохозяйственной отрасли в высококомпетентных кадрах на перспективу;

- совершенствование системы профориентации по специальностям и профессиям, наиболее востребованным на рынке труда с учетом имеющегося социального потенциала;

- стимулирование наставничества путем эффективного использования социального потенциала возрастных специалистов;

- расширение ресурсов в сфере здравоохранения и социального обеспечения;

- предоставление возможности получения непрерывного образования работниками отрасли;

- формирование средствами массовой информации позитивного образа специалиста сельского хозяйства;

- обеспечение достойных условий труда, а также улучшение материального и нематериального стимулирования персонала.

Система управления характеризуется взаимодействием составляющих ее элементов. Решение задач по совершенствованию профессиональных компетенций работников сельского хозяйства осуществляется на уровне государства, региона и конкретной организации с целью предотвращения наступления или углубления существующих вызовов и ограничений. В связи с этим предложения по формированию, реализации и контролю в области стратегического управления на уровне регионов и страны в целом следующие:

- нормативно-правовое обеспечение, а именно подготовка стратегий и концепций государственной кадровой политики сельскохозяйственной отрасли;

- методическое обеспечение путем разработки учебных программ для целевой под- готовки высококомпетентных работников с разным уровнем образования;

- материально-финансовое обеспечение профессионального развития работников сельского хозяйства и меры их социальной поддержки.

Совершенствование политики в области повышения квалификации и роста профессиональных компетенций работников сельского хозяйства необходимо проводить комплексно в масштабах страны, области, муниципального района и конкретной организации с учетом специфики личностного, социального и трудового потенциалов через предоставление консультационных услуг, информационных сервисов, инновационных технологий государственных и негосударственных центров профессиональной подготовки и переподготовки.

\section{СПИСОК ЛИТЕРАТУРЫ}

Бочарова 2017 - Бочарова Е.В. Система компетенций работников агропромышленного комплекса // Историческая и социально-образовательная мысль. 2017. Т. 9, № 5/1. С. 133-140.

Ефремова 2010 - Еремова Н.Ф. Формирование и оценивание компетенций в образовании: монография. Ростов н/Д: Аркол, 2010. 408 с.

Национальные проекты... web - Национальные проекты: ключевые цели и ожидаемые результаты // http://government.ru/projects/selection/ $741 / 35675$.

О внесении изменений... web - О внесении изменений в государственную программу «Содействие занятости населения»// http:// government.ru/docs/31938.

О переводе... web - О переводе Государственной программы развития сельского хозяйства и регулирования рынков сельскохозяйственной продукции, сырья и продовольствия на 20132020 годы на проектное управление // http:// government.ru/docs/30726.

Постановление Правительства РФ от 25 августа 2017 года... web - Постановление Правительства РФ от 25 августа 2017 года № 996 «Об утверждении Федеральной научно-технической программы развития сельского хозяйства на 20172025 годы». Доступ из информ.-правового портала «Гарант.ру».

Предварительные итоги... 2017 - Предварительные итоги Всероссийской сельскохозяйственной переписи 2016 года. В 2 т. Т. 1. М.: Статистика России, 2017. 
Рабочая сила, занятость... 2018 - Рабочая сила, занятость и безработица в России (по результатам выборочных обследований рабочей силы). М.: Росстат, 2018.

Российский мониторинг... web - «Российский мониторинг экономического положения и здоровья населения НИУ-ВШЭ (RLMS-HSE)», проводимый Национальным исследовательским университетом «Высшая школа экономики» и ООО «Демоскоп» при участии Центра народонаселения Университета Северной Каролины в Чапел Хилле и Института социологии $\mathrm{PAH} / /$ http://www.hse.ru/rlms.

Указ Президента РФ от 7 мая 2018 года... web - Указ Президента РФ от 7 мая 2018 года № 204 «О национальных целях и стратегических задачах развития Российской Федерации на период до 2024 года» // http://kremlin.ru/events/president/ news $/ 57425$.

Хуторской 2003 - Хуторской А.В. Ключевые компетенции как компонент личностно-ориентированной парадигмы образования // Народное образование. 2003. № 2. С. 58-64.

Chi 2006 - Chi M.T.H. Two Approaches to the Study of Experts' Characteristics // The Cambridge Handbook of Expertise and Expert Performance. N.Y.: Cambridge University Press, 2006. P. 21-30.

McClelland 1973 - McClelland D.C. Testing for Competence Rather Than for "Intelligence" // American Psychologist. 1973. Vol. 28. P. 1-14.

Winterton, Delamare Le Deist, Stringfellow 2006 Winterton J., Delamare Le Deist F., Stringfellow E. Typology of Knowledge, Skills and Competences: Clarification of the Concept and Prototype. Luxembourg: Office for Official Publications of the European Communities, 2006.

White 1959 - White R.W. Motivation Reconsidered: The Concept of Competence // Psychological Review. 1959. Vol. 66, № 5. P. 297-332.

\section{REFERENCES}

Bocharova E.V., 2017. System of Competences of Employees of Agro-Industrial Complex. Istoricheskaya i sotsialno-obrazovatelnaya mysl, vol. 9, no. 5/1, pp. 133-140.

Efremova N.F., 2010. Formation and Evaluation of Competences in Education. Monograph. Rostov-on-don, Arkol Publ.

National Projects: Key Objectives and Expected Results. URL: http:/government.ru/projects/ selection/741/35675.

About Modification of the State Program "Assistance of employment of the population". URL: http:// government.ru/docs/31938.
On the Transfer of the State Program for the Development of Agriculture and Regulation of Agricultural Products, Raw Materials and Food Markets for 2013-2020 to Project Management. URL: http://government.ru/docs/ 30726.

Resolution of the Government of the Russian Federation of August 25, 2017 no. 996 "On Approval of the Federal Scientific and Technical Program for the Development of Agriculture for 2017-2025". Access from "Garant" Informational and Legal Web Portal.

Preliminary Results of the 2016 All-Russian Agricultural Census, 2017. Moscow, Statistika Rossii Publ.

Labour Force, Employment and Unemployment in Russia (Based on the Results of Sample Labour Force Surveys), 2018. Moscow, Rosstat Publ.

The "Russian Monitoring of an Economic Situation and Health of the Population of Higher School of Economics National Research University (RLMS-HSE)" which is Carried out by the National Research University "Higher School of Economics" and LLC Demoskop with the Assistance of the Center of the Population of the University of North Carolina in Chapel Hille and Instituta of sociology of the Russian Academy of Sciences. URL: http://www.hse.ru/ rlms.

Presidential Decree of May 7, 2018 no. 204 "On the National Goals and Strategic Objectives of the Development of the Russian Federation for the period up to 2024". URL: http://kremlin.ru/ events/president/news/57425.

Khutorskoy A.V., 2003. Key Competences as a Component of the Personality-Oriented Paradigm of Education. Narodnoe obrazovanie, no. 2, pp. 58-64.

Chi M.T.H., 2006. Two Approaches to the Study of Experts' Characteristics. The Cambridge Handbook of Expertise and Expert Performance. New York, Cambridge University Press, pp. 21-30.

McClelland D.C., 1973. Testing for Competence Rather Than for "Intelligence". American Psychologist, vol. 28, pp. 1-14.

Winterton J., Delamare Le Deist F., Stringfellow E., 2006. Typology of Knowledge, Skills and Competences: Clarification of the Concept and Prototype. Luxembourg, Office for Official Publications of the European Communities.

White R.W.,1959. Motivation Reconsidered: The Concept of Competence. Psychological Review, vol. 66 , no. 5, pp. 297-332. 
E.B. Бочарова. Стратегические приоритеты совершенствования профессиональных компетенций

\section{Information About the Author}

Elena V. Bocharova, Candidate of Sciences (Sociology), Senior Researcher, Fellow of Laboratory of Social Development of the Agro-Industrial Complex and Rural Territories, Institute of Agrarian Problems of the Russian Academy of Sciences, Moskovskaya St, 94, 410012 Saratov, Russian Federation, kiril11979may@mail.ru, https://orcid.org/0000-0002-1757-5623

\section{Информация об авторе}

Елена Викторовна Бочарова, кандидат социологических наук, старший научный сотрудник лаборатории социального развития агропромышленного комплекса и сельских территорий, Институт аграрных проблем РАН, ул. Московская, 94, 410012 г. Саратов, Российская Федерация, kirill1979may@mail.ru, https://orcid.org/0000-0002-1757-5623 